\title{
Reinforcement of the Antioxidative Properties of Chickpea Beverages Through Fermentation Carried Out by Probiotic Strain Lactobacillus plantarum 299v
}

\author{
Katarzyna Skrzypczak ${ }^{1}$, Ewa Jabłońska- Ryś ${ }^{1 *}$, Klaudia Gustaw ${ }^{2}$, Aneta Sławińska ${ }^{1}$, \\ Adam Waśko ${ }^{2}$, Wojciech Radzki ${ }^{1}$, Monika Michalak-Majewska ${ }^{1}$ and Waldemar \\ Gustaw $^{1}$
}

${ }^{1}$ Department of Plant Food Technology and Gastronomy, Faculty of Food Science and Biotechnology, University of Life Sciences in Lublin, Skromna 8, 20-704 Lublin, Poland. '2Department of Biotechnology, Microbiology and Human Nutrition, Faculty of Food Science and Biotechnology, University of Life Sciences in Lublin, Skromna 8, 20-704 Lublin, Poland.

\begin{abstract}
The purpose of the research was to obtain different variants of chickpea beverages and subject them to probiotic fermentation carried out by Lactobacillus plantarum $299 \mathrm{v}$ in order to compare properties of received products. The study focused on the influence of the fermentation process on changes in protein profiles, antioxidative properties, $\mathrm{pH}$ values, and reducing power (RP). The analyzed variants of chickpea beverages exhibited diversity in terms of RP. Fermented products were characterized by significantly higher values of RP (A700) ranging from 0.1 to 0.29 than unfermented ones (value in range from 0.04 to 0.09 ). Whereas, $\mathrm{pH}$ values of fermented products were lower (from 4.46 to 5.64) to than unfermented beverages (6.68 to 7.57). The results indicate also the presence of $\beta$-conglycinin and glycinin (which are considered as one of food allergens) in analyzed chickpea-based beverages, however the probiotic fermentation contributed to strong hydrolysis of those components. Among tested variants of the chickpea products, the beverages with vanillin sugar and coconut flakes (unfermented as well as fermented) received the highest notes of general consumer acceptance in preliminary sensory assessment. The fermentation of the chickpea beverages with the probiotic strain significantly increased the reducing power of the products, revealed antioxidative-enhancing properties and contributed to hydrolysis of $\beta$-conglycinin (7S) and glycinin (11S) fractions.
\end{abstract}

Keywords: antioxidants, fermented chickpea beverages, probiotics.

*Correspondence: ewa.jablonska-rys@up.lublin.pl; +48 814623308

(Received: 17 November 2018; accepted: 24 January 2019)

Citation: Katarzyna Skrzypczak, Ewa Jabłońska- Ryś, Klaudia Gustaw, Aneta Sławińska, Adam Waśko, Wojciech Radzki, Monika Michalak-Majewska and Waldemar Gustaw, Reinforcement of the Antioxidative Properties of Chickpea Beverages Through Fermentation Carried Out by Probiotic Strain Lactobacillus plantarum 299v, J Pure Appl Microbiol., 2019; 13(1):01-12. doi: 10.22207/JPAM.13.1.01

C The Author(s) 2019. Open Access. This article is distributed under the terms of the Creative Commons Attribution 4.0 International License which permits unrestricted use, sharing, distribution, and reproduction in any medium, provided you give appropriate credit to the original author(s) and the source, provide a link to the Creative Commons license, and indicate if changes were made. 


\section{INTRODUCTION}

Due to their composition and nutritional quality, legumes are widely grown and constitute a staple food in some countries. They are a highly valuable source of proteins with biological significance with content in dry weight reaching the value from 20 to $40 \%$ (Boye et al., 2010). Therefore, pulses are often considered as some alimentary alternative in the diet, in which the supply of animal proteins is limited or completely eliminated e. g. because of some socioeconomical, cultural, religious, or health reasons (Boye et al., 2010; Sáez et al., 2017). Legumes as well as derived from them products constitute a rational alternative source of protein that may affect the lowering blood pressure and also exhibit a desirable influence on lipids metabolism (Jahreis et al., 2016). Additionally, in contemporary society, the increase in the number of individuals with diagnosed celiac disease contributes to directing more attention towards the possibilities of using legumes in production of a wide range of gluten-free products (including snacks, baked and extruded products with the use of alternative legume-origin flour) (Laleg et al., 2016). It has been claimed that flour derived from soy, lupin, chickpea and green pea are nutritionally important not only because constitute a great source of protein but there are also rich in dietary fiber (Jahreis et al., 2016). Moreover, seeds of pulses are rich in vitamins and minerals and constitute a good source of complex carbohydrates (Suárez-Martínez et al., 2016).

Some recent epidemiological studies have revealed that diets characterized by a higher intake of vegetables and fruits significantly decrease the level of risk of illnesses related to oxidative stress caused by accumulation of free radicals (Chen and Chen, 2013).

It is known that legumes exhibit high content of isoflavones, which are powerful antioxidants, and phytosterols i.e. cholesterollowering factors (Bouchenak and Lamri-Senhadji, 2013). Moreover, it has been suggested that regular consumption of legumes can reduce the risk of some civilization diseases including obesity, cardiovascular disease, diabetes, or even cancer (Bouchenak and Lamri-Senhadji, 2013; Finley et al., 2013; Xiao et al., 2015).

The properties of legume proteins such their water binding capacity, fat absorption, gelation, or foaming contribute to the high functional potential that could be applied in food industry and in designing new products. Furthermore, the high nutritional properties and presence of various bioactive phytochemicals (e.g. polyphenols and biopeptides) exhibited by this type of plants facilitate development of new functional food products (Boye et al., 2010; Campos-Vega et al., 2010; Calinoiu and Vodnar, 2018).

Constantly increasing global production of legumes has been observed recently ( $A$ / RES/68/231, FAO-WHO, 2015). According to available data, the world production of chickpea (Cicer arientum L.), which belongs to pulses, achieved a level of 12 million tons in 2016 (http:// www.fao.org/faostat/en/\#data/QC).

Chickpea is considered as a suitable source of dietary proteins exhibiting good balance of amino acid composition and high bioavailability; moreover, the seeds contain a low-fat level but are rich in glutathione, some vitamins like thiamine or niacin, and minerals ( $\mathrm{Ca}, \mathrm{Mg}, \mathrm{Zn}, \mathrm{K}, \mathrm{Fe}, \mathrm{P}$ ) (Boye et al., 2010; Esmat et al., 2010). In terms of nutritional quality, chickpea is suggested to be better than other legumes. Moreover, the healthpromoting effect connected with consumption of chickpea and, type 2 diabetes, or cancer have already been proved (Jukanti et al., 2012; Wallace et al., 2016; Zafar and Kabir, 2016; Gupta et al., 2018).

However, besides the wide range of desirable properties and valuable nutrients, legumes contain compounds that are commonly recognized as anti-nutritional factors (such as trypsin inhibitors, tannin, phytates, and saponins). In addition, they are responsible for weaker bioavailability of some nutritional components (by interfering with digestion and absorption) and can lead to occurrence of digestive discomfort (Khokhar and Owusu Apenten, 2009; Ghamari et al., 2014). Nonetheless, fermentation of raw plant materials seems to be an effective processing technique leading to reduction or even elimination of the undesirable nutritional factors in legumes. Furthermore, this bioprocess is dependent on the activity of different microorganisms (including lactic acid bacteria) and can enhance the nutraceutical profile, improve micronutrient 
bioavailability and dietary characteristics, and influence positively the sensory and functional properties of products derived from pulses (Rizzello et al., 2016; Ciesarová et al., 2017; Sáez et al., 2017) and wheat bran (Pasqualone et al., 2018).

Fermented plant-derived food products can also be carriers of probiotic bacteria, which is related to a wide range of beneficial health effects. Such functional food products could be an alternative to conventional probiotic milkbased products suitable for individuals that have to restrict the consumption of dairy products due to lactose intolerance, cow's milk allergy including cow's milk protein allergy (CMPA) and adverse reactions to cow's milk protein (CMP), low-protein diet, infant's diet, phenylketonuria (Nלmevkova et al., 2011; Dupont et al., 2012). Therefore, the objective of this investigation was to prepare novel chickpea beverages in various flavor variants and subject them to a fermentation process carried out by Lactobacillus plantarum $299 v$, i.e. a probiotic bacterial strain. The study focused on the influence of the fermentation process on changes in the $\mathrm{pH}$ values, antioxidant properties, and reducing power. The aim of the research was also to compare changes in the protein profiles after the process of probiotic fermentation conducted in different variants of chickpea beverages. Moreover, preliminary sensory assessment was conducted in order to determine whether the obtained new chickpeabased drinks exhibit potential to meet consumers' interest and acceptance.

\section{MATERIALS AND METHODS \\ Materials and reagents}

The organic chickpea seeds of Kabuli type (EU organic production logo - PL-EKO-01) constituting a raw plant material in the research were purchased from a local market (Table 1). Chemical reagents, i.e. 2-mercaptoethanol; potassium ferricyanide $\mathrm{K}_{3}\left[\mathrm{Fe}(\mathrm{CN})_{6}\right]$; 1,1-diphenyl2-picrylhydrazyl radical (DPPH); ferric chloride $\left(\mathrm{FeCl}_{3}\right)$, trichloroacetic acid (TCA), and L-ascorbic acid, were acquired from Sigma Aldrich (St. Louis, MO, USA). Acetic acid, ethanol, and methanol were purchased from POCh (Gliwice, Poland). The chemicals and solvents were analytical grade. All reagents used to prepare polyacrylamide
Table 1. Specification of the raw plant material according to the manufacturer's declaration (Symbio, Poland S.A.)

\begin{tabular}{ll}
\hline $\begin{array}{l}\text { Nutritional } \\
\text { values }\end{array}$ & $\begin{array}{l}\text { in } 100 \mathrm{~g} \text { of the } \\
\text { product }\end{array}$ \\
\hline $\begin{array}{l}\text { Energy } \\
\text { Protein }\end{array}$ & $1297 \mathrm{~kJ} / 310 \mathrm{kcal}$ \\
Carbohydrates & $19 \mathrm{~g}$ \\
- sugars & $44 \mathrm{~g}$ \\
Fat total & $2,3 \mathrm{~g}$ \\
- saturated & $5,9 \mathrm{~g}$ \\
fatty acids & $1,1 \mathrm{~g}$ \\
Fiber & $16 \mathrm{~g}$ \\
Salt & $0,09 \mathrm{~g}$ \\
\hline
\end{tabular}

Reference intake value for an average adult (8400 kJ / 2000 kcal)

electrophoresis (molecular biology grade) were obtained from Bio-Rad Laboratories (Hercules, California).

\section{Bacterial strain}

In the study, the probiotic strain Lactobacillus plantarum 299v (Sanprobi IBS, Sanum Poland) was used as a starter culture in the fermentation process.

\section{Preparation and fermentation of chickpea beverages}

The chickpea drinks were prepared according to Saraniya and Jeevaratnam (2015) using a device for making soybean milk (Food processor SMM200S, MANTA, China).

The beverages were produced in the following flavor variants: with $2 \%(\mathrm{v} / \mathrm{v})$ addition of soy sauce or with addition of vanillin sugar $2.5 \%(\mathrm{w} / \mathrm{v})$ and coconut flakes $2 \%(\mathrm{w} / \mathrm{v})$, while beverages without any addition were a control variant. Subsequently, all variants were tightly covered and pasteurized in a water bath $\left(85^{\circ} \mathrm{C} / 15\right.$ min). Then, after cooling to $37^{\circ} \mathrm{C}$, all samples were inoculated (under sterile conditions) with a lyophilizate $(20 \mathrm{~g} / \mathrm{L})$ of the probiotic strain (number of viable bacterial cells at the level of $10^{9} \mathrm{cfu} / \mathrm{mL}$ ) and incubated at $35^{\circ} \mathrm{C}$ for $18 \mathrm{~h}$.

The changes in the $\mathrm{pH}$ value (before and after the fermentation process) were determined using the $\mathrm{pH}$ meter Hanna Instruments HI 221 (Hanna Instruments, Poland).

\section{Antioxidant activity}

The radical scavenging activities of the 
unfermented and fermented products were evaluated according to the method described by Li et al. (2015) using an alcoholic DPPH - solution. The radical scavenging activity of the analyzed samples was expressed as \% inhibition of DPPHabsorbance $(\lambda=517 \mathrm{~nm}$ ) that was calculated using the following equation:

$$
\text { Inhibition }[\%]=\left[\left(A_{\text {control }}-A_{\text {test }}\right) / A_{\text {control }}\right] \times 100
$$

where: $A_{\text {control }}$ is the absorbance $(\lambda=517$ $\mathrm{nm}$ ) of the control sample (DPPH solution without any of the analyzed product sample) and $A_{\text {test }}$ is the absorbance of the analyzed sample (DPPHsolution containing a sample of a fermented or unfermented beverage).

The absorbance measurement was performed using a SmartSpec ${ }^{\text {TM }}$ Plus Spectrophotometer (Bio-Rad Laboratories, Hercules, California).

\section{Reducing power}

The value of reducing power in the samples of the prepared beverages (before and after fermentation) was determined spectrophotometrically $(\lambda=700 \mathrm{~nm}$ ) according to the method described by El-Fattah et al. (2016). Ascorbic acid $(0.2 \mathrm{mmol} / \mathrm{L}$ ) was used as a positive control. An increase in the absorbance value of the analyzed reaction mixture indicated higher reducing power.

\section{Protein Extraction}

The protein fractions from unfermented and fermented drink samples were obtained according to the extraction method described by Bao et al. (2014). The soluble protein content was detected with the Bradford method, using bovine serum protein as a standard (BSA, Sigma, USA). Then, the protein profiles of the analyzed samples were detected using SDS-polyacrylamide gel electrophoresis (SDS-PAGE) performed according to Zhang et al. (2014).

\section{Preliminary sensory assessment}

Semi-consumer sensory analysis was performed with the use of a 9-point hedonic scale (Trząskowska et al., 2018), where 1 stood for "extremely dislike" and 9 for "extremely like". The sensory tests were performed in conditions described by Wójtowicz et al. (2018). A laboratory room with bright natural daylight was the environment of the analysis. All samples were marked with codes and were randomly provided to evaluators on white plates. The assessment focused on such parameters as smell, flavor, color, and consistency. Moreover, the general acceptability of the tested samples in relation to consumers' preferences was also analyzed. The evaluation panel consisted of ten people. All participants involved in the assessment were thoroughly informed about each of the tested sensory attributes.

\section{Statistical analysis}

Statistical analysis was conducted using the Statistica 13.1 (StatSoft, Poland) program. Analysis of variance (ANOVA) followed by Tukey's post-hoc test was performed to determine significant differences $(P<0.05)$ among the average values of the parameters measured.

\section{RESULTS AND DISCUSSION Antioxidant activity}

Most of the pathogenic changes underlying diseases affecting a large part of the population are related to effects caused by free radical activity. The imbalance between reactive free radicals accumulated in the organism and the efficiency of antioxidant systems leads to oxidative stress that is related to neurode-generative diseases, coronary heart disease, arthritis, emphysema, gastrointestinal disorders, diabetes, cirrhosis, atherosclerosis, and cancer (Marazza et al., 2012; Shahidi et al., 2012; Saha et al., 2017).

The activity of antioxidants is associated with the ability to scavenge free radicals, prevent formation of radicals, and enhance the production of hydrogen peroxide and other peroxides. However, it has been demonstrated that some synthetic antioxidative substances might cause some side effects and pose a potential risk in vivo; therefore, their use as food additives is limited or even prohibited in some countries (Osuntoki and Korie, 2010; Abubakr et al., 2012). For this reason, antioxidant compounds derived from natural sources are extremely valuable and a search for new natural antioxidants is an object of many scientific investigations.

As shown in Figure 1, the analyzed samples derived from fermented products exhibited a significantly $(P<0.05)$ higher capacity to scavenge DPPH radicals than the unfermented beverages. The analysis revealed that the enhancement of the 
antioxidative properties of the chickpea beverages was associated with the fermentation process. The results coincide with the findings demonstrated by Xiao et al. (2014), who investigated the antioxidant capacity of chickpeas after solid-state fermentation carried out by Cordyceps militaris SN-18.

The increased antioxidative properties of chickpea drinks fermented by L. plantarum 299v may be related to the higher phenolic content. Similar results were obtained by Pasqualone et al. (2018) in a phenolic-rich fermented beverage of wheat bran. Also, McCue and Shetty (2005) noted that bioprocessing of soymilk with the use of diverse kefir microflora (Lactobacillus plantarum, Lactobacillus casei, Saccharomyces fragilis, Streptococcus lactis, Streptococcus cremoris, Streptococcus diacetylactis, and Leuconostoc cremoris) increased the content of phenolic compounds. These results are supported by other findings demonstrated by Lee et al. (2008), indicating that the activity of $\beta$-glucosidase synthesized by some microorganisms contributed to an increase in the content of polyphenols. Moreover, fermentation of another legumederived product (cowpea flour) with the use of
L. plantarum was positively correlated with an increase in the content of phenols as well (Dueñas et al., 2005).

Chickpea proteins are the other components with confirmed antioxidative properties (Yust et al., 2012; Kou et al., 2013; Torres-Fuentes et al., 2014; 2015). In addition to the biochemical transformations of sugars occurring during the fermentation carried out by a starter culture, proteins are hydrolyzed by proteolytic enzymes of microorganisms. Peptides and amino acids generated through proteolysis are also involved in the process of free radical scavenging. Since legumes (including chickpea) are a valuable source of proteins, they are considered as precursors of amino acid sequences exhibiting high antioxidative potential. In terms of the antioxidant properties, especially strong activity is exhibited by peptide sequences with histidine or arginine located at the C-terminus (Li and Li, 2013). Similarly, a study conducted by Torres-Fuentes et al. (2015) indicates that the presence of histidine identified in a majority of peptide fractions of chickpea is one of the determinants of its antioxidant activity. Furthermore, in lipid systems, hydrophobic amino acids exert a particularly

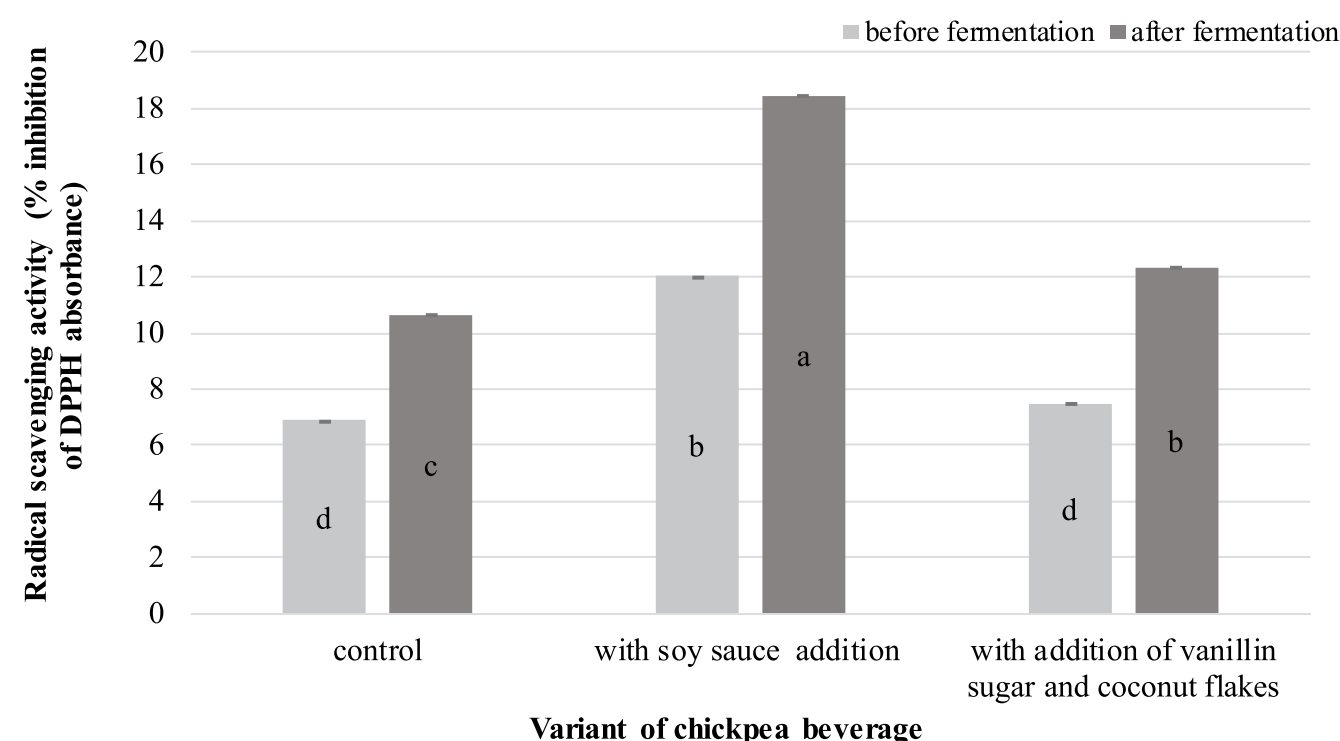

Fig. 1. Antioxidative activities exhibited by the analyzed chickpea beverages

Explanatory notes: Mean values \pm mean standard deviation $(x \pm s / S D ; n=3)$ with different letters indicate statistically significant difference $(P<0.05)$ 
significant antioxidative effect mainly due to their capacity to enhance the solubility of lipids (Saiga et al., 2003).

As shown in Figure 1, the fermented beverage containing soy sauce is definitely distinguished among all products in terms of its free radical scavenging properties. The highest value of antioxidative activity recorded for this chickpea drink variant may be associated with the incorporated soy-derived addition. A similar tendency to increase the radical scavenging activity after the fermentation process was noted in analysis of soy whey fermented by L. plantarum B1-6 (Xiao et al., 2015).

Kim et al. (2011) suggested that increased scavenging activity in fermented soy products is related to an increase in the total phenolic content (TPC) and higher level of isoflavone aglycones. Moreover, a study conducted by Marazza et al. (2012) revealed that an increase in the iso avone aglycone content during soymilk fermentation by Lactobacillus rhamnosus was a result of $\beta$-glucosidase activity towards iso avone glucosides. It was also claimed that the isoflavone aglycones generated during fermentation had higher antiradical activity than iso avone glucosides. This may explain the results obtained in the present study, where the greater radical scavenging activity exhibited by the fermented chickpea beverage containing soy sauce (in comparison to the other analyzed products) might be due to the higher content of isoflavone aglycones and TPC.

\section{Reducing power (RP)}

As shown Figure 2, the reducing power (RP) of the analyzed chickpea beverages varied and achieved a value between 0.06 (unfermented control sample) and 0.21 (fermented chickpea drinks with addition of vanillin sugar and coconut flakes).

It was also noted that the extracts from the fermented products were characterized by significantly higher $(P<0.05)$ values of RP than the samples of the unfermented beverages. Similar observations were noted by Xiao et al. (2014) in analysis of the reducing power of methanolic, ethanolic, and water extracts derived from chickpeas before and after solid-state fermentation carried out by an entomogenous fungus Cordyceps militaris (L.). The research showed that the methanolic extract of the fermented product exhibited 3.3-fold stronger reducing power than that in the corresponding unfermented sample. In turn, among the analyzed chickpea beverages, the highest increase in RP after fermentation was noted in the variant with the addition of vanillin sugar and coconut flakes (the value of this parameter was more than four

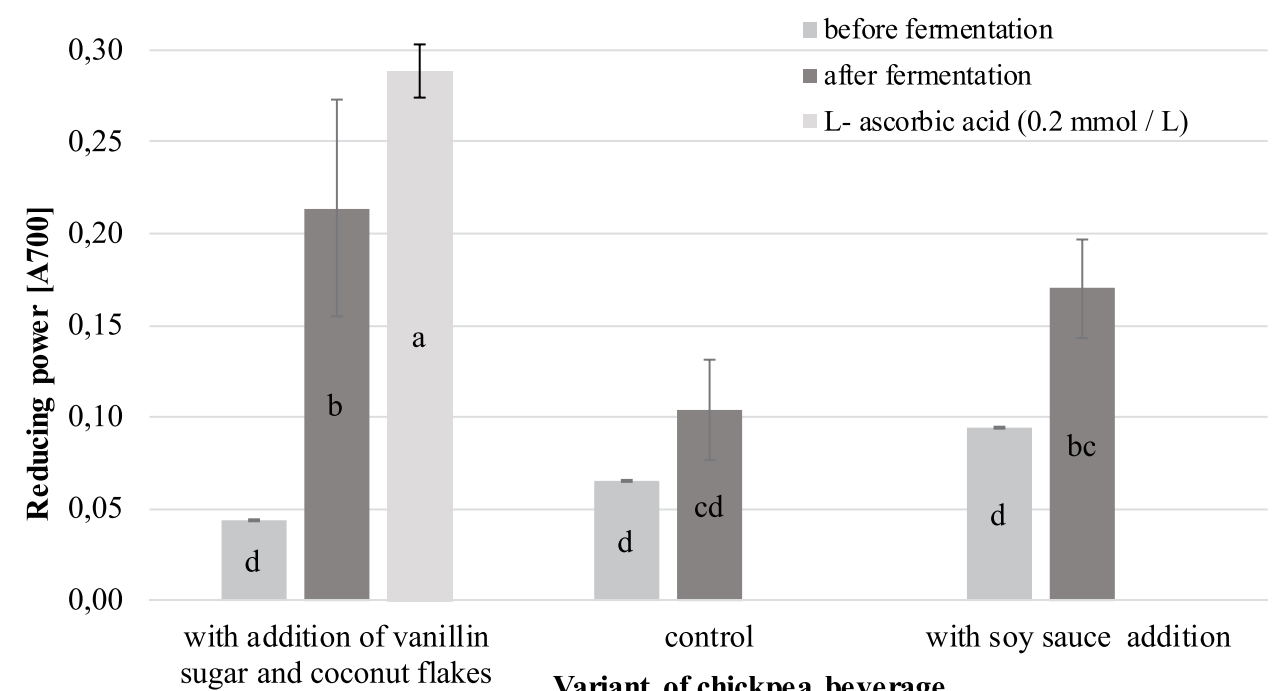

Fig. 2. Comparison of the reducing power exhibited by the analyzed chickpea beverages

Explanatory notes: Mean values \pm mean standard deviation $(x \pm s / S D ; n=3)$ with different letters indicate statistically significant difference $(\mathrm{P}<0.05)$ 
times higher than in the unfermented analog). Interestingly, this variant exhibited the lowest $\mathrm{pH}$ equal to 4.46 (Figure 3). The same relationship between RP and $\mathrm{pH}$ values was noted by Zhao and Shah (2014), who revealed that the highest values of RP was noted for a hydrophilic extract of fermented soy milk characterized by the lowest $\mathrm{pH}(\mathrm{pH} 3.85)$.

The results of the analysis of the $\mathrm{pH}$ changes (Figure 3 ) in fermented chickpea beverages correspond to the findings described by Chandra-Hioe et al. (2016), who noted pH between 4.6 and 4.9 in samples of chickpea and faba bean after $16 \mathrm{~h}$ fermentation carried out by Lactobacillus bacteria.

The presented results of the level of RP for the different variants of chickpea beverages are in agreement with findings described by Xiao et al. (2015), who noted that fermentation of soy whey by Lactobacillus plantarum B1-6 increased the value of RP. They also proved that fermented products provided greater protection against oxidative DNA damage induced by Fenton reagent.

The results of $\mathrm{RP}$ obtained for the fermented beverages with soy sauce addition (value over 0.1) were similar to values obtained for a chickpea protein isolate in studies conducted by Yust et al. (2012). Interestingly, the value of this parameter for the fermented beverages with the addition of vanillin sugar and coconut flakes corresponds to results noted by the authors for samples of chickpea protein hydrolyzates obtained after $60 \mathrm{~min}$ of hydrolysis with alcalase followed by 120 min of hydrolysis with flavourzyme.

It was previously described by Lee et al. (2008) that the reducing power is associated with the presence and hydrogen-donating ability of reductones. Therefore, the positive influence of the fermentation conducted by the probiotic strain (L. plantarum 299v) on increasing the values of RP of the chickpea drinks may be explained by generation (during the process of fermentation) of substances with reducing activity interacting with free radicals. This leads to stabilization and termination of radical chain reactions contributing to stronger reducing power of fermented products (Xiao et al., 2014).

Moreover, it has been suggested that an increased reducing ability is connected with the hydrogen-donating properties of intracellular antioxidants and peptides of microorganisms involved in the fermentation process (Lin et al., 2006). This may also be reflected in the results of protein profile analysis in the tested chickpea beverages described below.

\section{Protein profiles}

The results of electrophoresis analysis of the analyzed beverage extracts (Figure 4.) indicate that the major protein subunits identified in the unfermented chickpea drinks exhibit similarity to

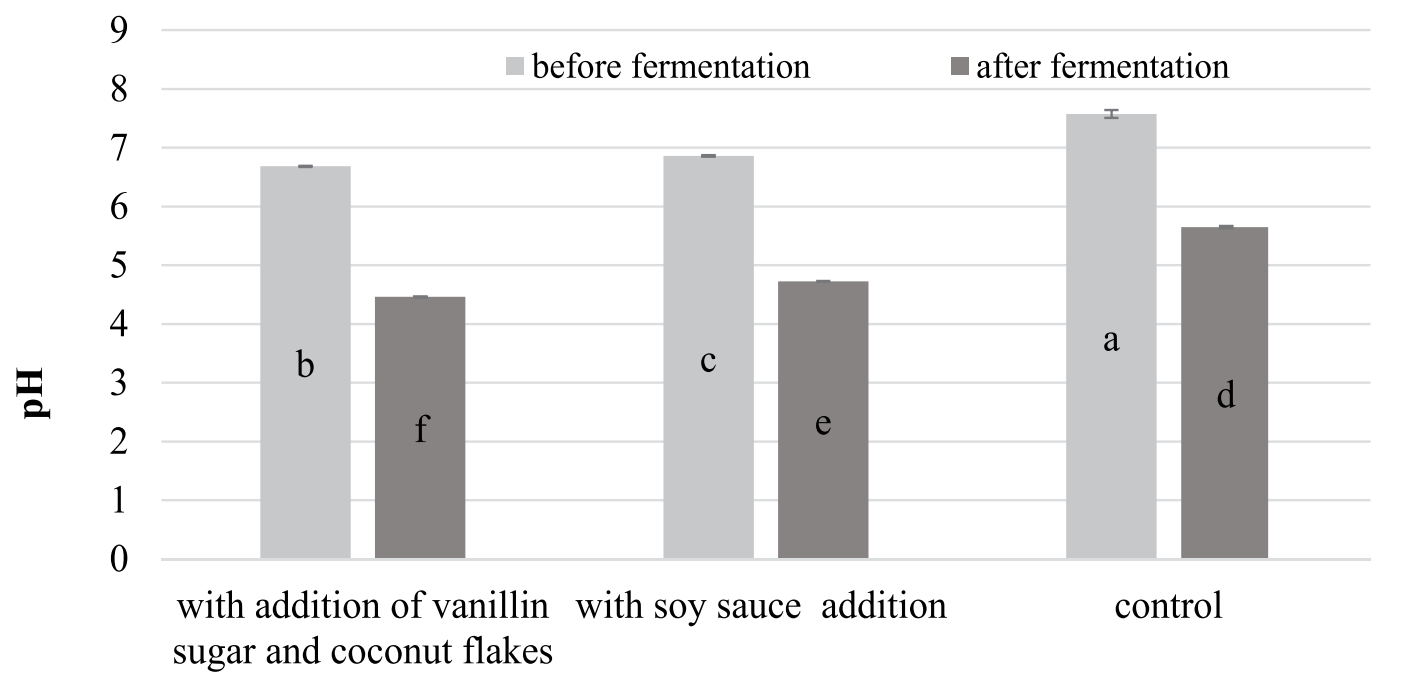

Fig. 3. Comparison of the changes in $\mathrm{pH}$ values in the chickpea beverages after the fermentation process. Explanatory notes: Mean values \pm mean standard deviation $(x \pm s / S D ; n=3)$ with different letters indicate statistically significant difference $(P<0.05)$ 
subunits detected in samples of soybean flour: 7S ( $\beta$-conglycinin) consisting of $\alpha$ and $\beta$ subunits and glycinin (11S) containing basic subunits (B) and acidic subunits (A) (Abu-Salem et al., 2013).

The patterns of protein profiles obtained for the unfermented beverages samples are similar to SDS-PAGE patterns of a chickpea extract analyzed by Chang et al. (2012). They identified legumin $\alpha$-subunits with molecular mass of 40.6 and $39.5 \mathrm{kDa}$, legumin $\beta$-subunits (23.5 and $22.5 \mathrm{kDa})$, and vicilin subunits $(70.2,50.7,35.0$, 33.6, 18.9 and $15.5 \mathrm{kDa}$ ) in the chickpea seed material. Moreover, Sánchez-Vioque et al. (1999) suggested that $11 \mathrm{~S}$ protein subunits exhibiting molecular masses in a range between 46.5-39.8 and 25.3-24.3 kDa identified in chickpea are comparable to soybean $11 \mathrm{~S}$ subunits. Products with molecular mass specific for the range of the chickpea $11 \mathrm{~S}$ protein subunits were also visible in all the analyzed profiles of the unfermented beverages samples (Figure 4: lanes 1, 3, and 5).

The present findings are also consistent with other analysis results showing that the estimated molecular masses of chickpea vicilin subunits are comparable to some of the soybean $7 S \beta$-conglycinin subunits (Krishnan et al., 2009; Chang et al., 2012; Abu-Salem et al., 2013). In addition, the $11 \mathrm{~S}, 7 \mathrm{~S}$ ( $\beta$-conglycinin consisting of $\alpha_{-}, \alpha^{\prime}-$, and $\beta$-subunits of approximately 72,70 , and $52 \mathrm{kDa}$ ), and $2 \mathrm{~S}$ globulin fractions identified in soybean are considered as food allergens. Moreover, $7 \mathrm{~S}$ is one of the most allergenic proteins, as confirmed by investigations conducted by Krishnan et al. (2009), who proved that all three subunits of $\beta$-conglycinin are potential food allergens. Interestingly, the products with molecular masses corresponding to the 75 and $11 S$ subunit obtained in the analyses were mainly present in the unfermented chickpea drinks (Figure 4: lanes: 1, 3, and 5). In turn, after the fermentation carried out by L. plantarum 299v, most proteins in the range of 90-38 kDa were not detected on the gel except from the variant of the fermented drink with the addition of soy sauce (Figure 4: lane 2). However, the product with molecular mass of approximately 52 kDa (Figure 4: lane 2) visible in the protein profile of this beverage variant may be a soy-derived protein that was incorporated into the drink together with the addition of soy sauce. The results indicate that the fermentation process of chickpea beverages conducted by the analyzed probiotic strain can reduce the content of proteins that are considered as potential allergens.

The differences in the hydrolyzates observed after the fermentation process may be caused by different preference and specificity (cleavage site) of the bacterial proteolytic enzymes to individual proteins from the protein matrix of

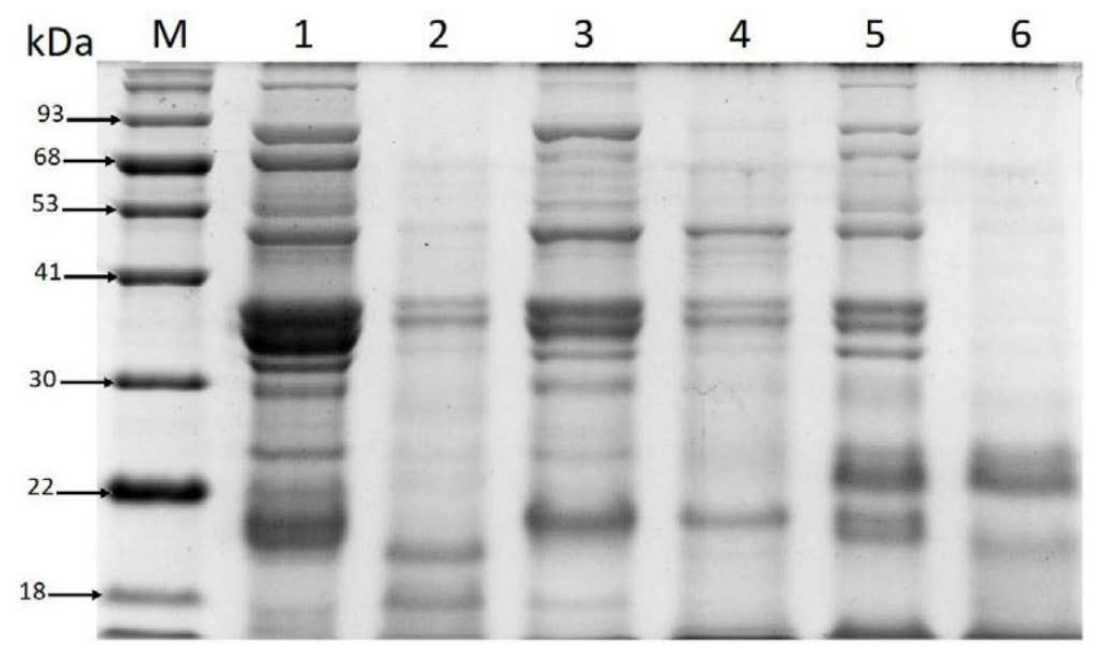

Fig. 4. Comparison of protein profiles in the extracts of the analyzed chickpea beverages Explanatory notes: Chickpea beverage variants: natural without any flavor additives (Lane 1- unfermented, Lane 2- fermented); with soy sauce addition (Lane 3- unfermented, Lane 4- fermented); with addition of vanillin sugar and coconut flakes (Lane 5unfermented, Lane 6- fermented); Lane M" protein standard marker 
the chickpea-derived drinks (the supplementation of soy sauce or coconut flakes increased the pool of different proteins and peptide sequences).

The protein profile of the fermented chickpea drink containing vanillin sugar and coconut flakes is characterized by the highest degree of hydrolysis (Figure 4: lane 6).

\section{Preliminary sensory assessment}

The semi-consumer evaluation is performed to determine consumer preferences and analyze the degree of desirability of the tested food products. The basic criterion for the consumer acceptance of the assessed food product depends on its sensory attractiveness, nutritional value, and safety. Undoubtedly the features influencing sensory attractiveness include such parameters as color, aroma, and consistency, which together with palatability, availability, and health aspects shape the overall quality of the food product. Therefore, preliminary sensory assessment was performed in order to determine whether the new chickpea-based drinks produced as part of the pilot research exhibit potential to win consumers' interest and acceptance.

The results show (Table 2 ) the highest score $(8.1 \pm 0.72)$ of general acceptance for the unfermented beverage variant containing vanillin sugar and coconut flakes. This kind of chickpea drinks was distinguished among the others by the highest notes in the flavor and smell assessment as well $(8.0 \pm 1.34$ and $8.0 \pm 0.67$, respectively).
The unfermented control beverages and the unfermented drink variant containing soy sauce received very similar notes. However, in terms of consistency assessment, the product variant containing the addition of soy sauce was rated slightly higher $(6.5 \pm 1.79)$; nonetheless, the lowest level $(4.3 \pm 2.43)$ of general acceptance was noted for this variant of the fermented beverages (Table 2).

The fermentation process did not significantly $(P<0.05)$ change the assessment of such parameters as the color and consistency of the beverages. However, comparing the average values of the general acceptance assessment and other features included in the analysis, slightly lower notes were recorded for the fermented products than for their unfermented counterparts (Table 2). An exception was the beverage variant containing vanillin sugar and coconut flakes (Table 2). After fermentation, drinks of this variant obtained a higher score in the color assessment, while the notes for the other parameters did not significantly differ from those for the unfermented analog. Such high notes for this kind of beverages (fermented and unfermented) may be correlated with their subtly sweet taste resulting from the flavor additives used. In turn, the unfermented chickpea drink (control) was characterized by the lowest level of general acceptance, which may be associated with the too neutral taste of this product variant. Interestingly, the process

Table 2. Results of the preliminary sensory assessment of the chickpea beverages

\begin{tabular}{|c|c|c|c|c|c|c|}
\hline & \multirow[b]{2}{*}{$\begin{array}{c}\text { Chickpea beverage } \\
\text { variant }\end{array}$} & \multicolumn{5}{|c|}{ Evaluated parameter } \\
\hline & & Smell & Flavor & Color & Consistency & $\begin{array}{c}\text { General } \\
\text { acceptability }\end{array}$ \\
\hline \multirow[t]{3}{*}{ Unfermented } & control & $5.2 \pm 1.82^{\mathrm{bc}}$ & $3.7 \pm 1.03^{b}$ & $7.6 \pm 1.76^{a}$ & $5.6 \pm 1.79^{a}$ & $4.7 \pm 1.13^{\mathrm{bc}}$ \\
\hline & with soy sauce addition & $5.6 \pm 1.78^{\mathrm{bc}}$ & $4.7 \pm 2.9^{b}$ & $6.9 \pm 2.24^{\mathrm{a}}$ & $6.5 \pm 1.79^{a}$ & $5.4 \pm 2.26^{\mathrm{bc}}$ \\
\hline & $\begin{array}{l}\text { with addition of vanillin } \\
\text { sugar and coconut flakes }\end{array}$ & $8.0 \pm 0.67^{a}$ & $8,0 \pm 1.34^{a}$ & $6.5 \pm 1.36^{a}$ & $6.1 \pm 1.66^{\mathrm{a}}$ & $8.1 \pm 0.72^{\mathrm{a}}$ \\
\hline \multirow[t]{3}{*}{ Fermented } & control & $4.7 \pm 1.45^{c}$ & $3.7 \pm 1.38^{b}$ & $7.5 \pm 1.76^{a}$ & $6.3 \pm 1.38^{a}$ & $4.7 \pm 1.45^{\text {bc }}$ \\
\hline & with soy sauce addition & $4.3 \pm 2.45^{c}$ & $4.2 \pm 2.82^{b}$ & $6.1 \pm 1.76^{a}$ & $6.2 \pm 2.14^{\mathrm{a}}$ & $4.3 \pm 2.43^{c}$ \\
\hline & $\begin{array}{l}\text { with addition of vanillin } \\
\text { sugar and coconut flakes }\end{array}$ & $7.4 \pm 1.43^{\mathrm{ab}}$ & $7.3 \pm 0.79^{a}$ & $7.4 \pm 1.35^{\mathrm{a}}$ & $5.7 \pm 1.64^{\mathrm{a}}$ & $6.8 \pm 1.87^{a b}$ \\
\hline
\end{tabular}

Explanatory notes: Mean values \pm mean standard deviation $(x \pm s / S D ; n=10)$ in the same column refer to the evaluated parameter, the same letters indicate no statistically significant difference $(P<0.05)$ 
of probiotic fermentation did not significantly influence the note in the assessment of general acceptability of this variant of drinks.

However, it should be emphasized that the preliminary sensory assessment performed in the research depended on the subjective taste preferences of the panel assessing the products. Generally, the lower notes recorded for the control variant and for the drinks containing soy sauce may indicate greater consumers' preference for sweet rather than salty or neutral taste. Moreover, as indicated by the additional comments made by the participants of the assessment, the taste of the chickpea drinks with the addition of vanillin sugar and coconut flakes was comparable to sweet vanilla dairy desserts or vanilla puddings, while the fermented variant of these products resembled cheesecake and homogenized vanillaflavored desserts. In turn, the taste and texture of the unfermented and fermented beverages containing soy sauce were mostly described as a taste similar to some vegetable or meat soups, dips, and sauces that are a salty addition to fish and meat dishes. This may indirectly indicate a possible target of application suggested for this type of food products.

Sensory analyses involving consumer assessment oriented for product development play a crucial role in food industry (SinghAckbarali and Maharaj, 2014). Therefore, further comprehensive research involving instrumental, physiochemical, and sensory analyses evaluating the intrinsic physical properties of the chickpeaderived products is highly required.

In conclusion, the initiative of designing new chickpea-derived drinks undertaken in this research fits in the recommendations of healthcare organizations regarding an increase in the consumption of leguminous plants. The results suggest that the analyzed fermented products can be an interesting proposition of novel legume beverages, which could be accepted by a wider range of consumers. Such (gluten- and lactose-free) products can be also carriers of probiotic strains, thus constituting an alternative to milk-derived foods. The fermentation of the chickpea beverages with the probiotic strain (Lactobacillus plantarum 299v) significantly increased the reducing power of the products (in particular in the variant with the addition of vanillin sugar and coconut flakes) and revealed antioxidative-enhancing properties (especially in the variant of drinks containing soy sauce). The present result also revealed the presence of $\beta$-conglycinin (7S) and glycinin (11S) in the chickpea-based drinks; however, the probiotic fermentation contributed to strong hydrolysis of these fractions. This suggests that the biotechnological process can significantly reduce the content of potentially allergenic components and increase the bioavailability of nutrients in the analyzed products. However, despite the promising research results, further investigations are undoubtedly required to identify and analyze the in vivo properties of individual components present in fermented legume-based drinks. The results of further research may demonstrate other desirable biologically active substances from chickpea or contribute to a more efficient use of L. plantarum $299 \mathrm{v}$ in the production of functional foods, nutraceuticals, supplements, or pharmaceuticals.

\section{ACKNOWLEDGEMENTS}

None

\section{CONFLICT OF INTEREST}

The authors declare that there is no conflict of interest.

\section{REFERENCES}

1. Boye J, Zare F, Pletch A. Pulse proteins: Processing, characterization, functional properties and applications in food and feed. Food Res. Int. 2010; 43: 414-431.

2. Sáez GD, Hébert EM, Saavedra L, Zárate G. Molecular identification and technological characterization of lactic acid bacteria isolated from fermented kidney beans flours (Phaseolus vulgaris L. and P. coccineus) in northwestern Argentina. Food Res. Int. 2017; 102: 605-615.

3. Jahreis G., Brese M, Leiterer M, Schäfer U, Böhm V Legume flours: Nutritionally important sources of protein and dietary fiber. Ernahrungs umschau 2016; 63: 36-42

4. Laleg K, Cassan D, Barron C, Prabhasankar P, Micard V. Structural, culinary, nutritional and anti-nutritional properties of high protein, gluten free, $100 \%$ legume pasta. PloS One. 2016; 11: 1-19.

5. Suárez-Martínez SE, Ferriz-Martínez RA, Campos-Vega R, Elton-Puente JE, de la Torre Carbot K, García-Gasca T. Bean seeds: Leading nutraceutical source for human health. CyTA-Journal of Food 2016; 14: 131-137.

6. Chen AY, Chen YC. A review of the dietary flavonoid, kaempferol on human health and cancer chemoprevention. Food Chem. 2013; 138: 2099-2107. Bouchenak M, Lamri-Senhadji M. Nutritional Quality 
of Legumes, and Their Role in Cardiometabolic Risk Prevention: A Review. J. Med. Food, 2013; 16: 1-14.

8. Finley JW, Sandlin C, Holliday DL, Keenan MJ, Prinyawiwatkul W, Zheng J. Legumes reduced intestinal fat deposition in the Caenorhabditis elegans model system. J. Funct. Foods, 2013; 5: 1487-1493.

9. Xiao $Y$, Wang L, Rui X, Li W, Chen X, Jiang M, Dong $M$. Enhancement of the antioxidant capacity of soywhey by fermentation with Lactobacillus plantarum B1-6. J. Funct. Foods, 2015; 12: 33-44.

10. Campos-Vega RG. Loarca-Pioa BD, Oomah C. Minor components of pulses and their potential impact on human health. Food Res. Int. 2010; 43: 461-482.

11. Calinoiu LF, Vodnar DC Whole Grains and Phenolic Acids: A Review on Bioactivity, Functionality, Health Benefits and Bioavailability. Nutrients 2018; E1615.

12. FAO-WHO (2015). Resolution adopted by the General Assembly on 20 December 2013, 68/231. International Year of Pulses 2016. A/RES/68/231 [http://www.fao. org/pulses-2016/en/ On line accessed 27 august, 2018]

13. http://www.fao.org/faostat/en/\#data/QC , Accessed 27 august, 2018.

14. Esmat AAA, Helmy IMF, Bareh GF. Nutritional Evaluation and Functional Properties of Chickpea (Cicer arietinum L.) Flour and the Improvement of Spaghetti Produced from its. J Am Sci. 2010; 6: 1057-1072.

15. Jukanti AK, Gaur PM, Gowda CL, Chibbar R.N. Nutritional quality and health benefits of chickpea (Cicer arietinum L.): A review. Br. J. Nutr. 2012; 108 (Suppl. 1): 11-26.

16. Wallace TC, Murray R, Zelman KM. The Nutritional Value and Health Benefits of Chickpeas and Hummus. Nutrients. 2016; 12:766.

17. Zafar TA, Kabir Y. Chickpeas suppress postprandial blood glucose concentration, and appetite and reduce energy intake at the next meal. J Food Sci Technol. 2016; 54:987-994.

18. Gupta N, Bisen PS, Bhagyawant SS. Chickpea Lectin Inhibits Human Breast Cancer Cell Proliferation and Induces Apoptosis Through Cell Cycle Arrest. Protein Pept Lett. 2018; 25: 492-499.

19. Khokhar S, Owusu Apenten RK. Antinutritional factors in food legumes and effects of processing. In: Squires V.R (ed.), The role of food, agriculture, forestry and fisheries in human nutrition Encyclopedia of Life Support Systems (EOLSS), Publishers Co Ltd. Oxford, UK, 2009, pp. 82-116.

20. Ghamari S, Mohammadi K, Khana-hmadzadeh A, Goli $\mathrm{H}$. Evaluation the Some Physical Properties of Chickpea Seeds in Kurdistan Region of Iran. IJAF, 2014; 4: 4-7.

21. Rizzello CG, Losito I, Facchini L, Katina K, Palmisano F, Gobbetti M, Coda R. Degradation of vicine, convicine and their aglycones during fermentation of faba bean flour. Sci. Rep. 2016; 6: 32452.

22. Ciesarová Z, Mikušová L, Magala M, Kohajdová Z, Karovičová J. 2017. Nonwheat Cereal-FermentedDerived Products. pp. 417-432. In Frias J, MartinezVillaluenga C, Peñas E (eds.), Fermented Foods in Health and Disease Prevention, Academic Press, London, UK., 2017, pp. 417-432.

23. Pasqualone A, Summo C, Laddomada B, Mudura
E, Coldea TE. Effect of processing variables on the physico-chemical characteristics and aroma of bors, a traditional beverage derived from wheat bran. Food Chem. 2018; 265: 242-252.

24. Němečková I, Dragounová $\mathrm{H}$, Pechačová $\mathrm{M}$, Rysová J, Roubal P. Fermentation of vegetable substrate by lactic acid bacteria as a basis of functional foods. Czech J. Food Sci. 2011; 29: 42-48.

25. Dupont $C$, Chouraqui JP, de Boissieu $D$, Bocquet $A$, Bresson JL, Briend A, Darmaun D, Frelut ML, Ghisolfi J, Girardet JP, Goulet O, Hankard R, Rieu D, Vidailhet M, Turck D; French Society of Paediatrics. Dietary treatment of cows' milk protein allergy in childhood: a commentary by the Committee on Nutrition of the French Society of Paediatrics. Br J Nutr. 2012; 107: 325-38

26. Saraniya A, Jeevaratnam K. In vitro probiotic evaluation of phytase producing Lactobacillus species isolated from Uttapam batter and their application in soy milk fermentation. J. Food Sci. Technol. 2015; 52: 5631-5640.

27. Li Y, Liu T, He G. Antioxidant activity of peptides from fermented milk with mix culture of lactic acid bacteria and yeast. Adv. J. Food Sci. Technol. 2015; 7: 422-427.

28. El-Fattah ABD, Sakr S, El-Dieb S, Elkashef H. Angiotensinconverting enzyme inhibition and antioxidant activity of commercial dairy starter cultures. Food Sci. Biotechnol. 2016; 25: 1745-1751.

29. Bao N, Qin G, Zhang P, Zhao Y, Sun Z, Li P. Strain screening for lowering immune activity of $\beta$-conglycinin in defatted whole soybean flour through fermentation. Can. J. Anim. Sci. 2014; 94: 427-436.

30. Zhang S, Zhang L, Jiao Y, Luo X, Li H, Xin L, Xue Ch, Zhang Y, Yi H, Han X, Ma Ch. Technological characterization of lactic acid bacteria protease isolated from traditional Chinese fermented milk. J Food Quality, 2014; 37: $395-402$.

31. Trząskowska M, Trzcińska A, Kapica Ż. Sensory quality and viability of potentially probiotic strains of Lactobacillus in fermented honey beverage. ŻYWNOŚć. Nauka. Technologia. Jakość. 2018; 114: 87 - 96.

32. Wójtowicz A, Zalewska-Korona M, JabłońskaRyś E, Skalicka-Woźniak K, Oniszczuk A. Chemical Characteristics and Physical Properties of Functional Snacks Enriched with Powdered Tomato. Pol. J. Food Nutr. Sci. 2018; 68: 251-261.

33. Marazza JA, Nazareno MA, de Giori GS, Garro MS. Enhancement of the antioxidant capacity of soymilk by fermentation with Lactobacillus rhamnosus. J. Funct Foods, 2012; 4: 594-601.

34. Shahidi F, Zhong Y, Chandrasekara A. Antioxidants and human health. In Yu L, Tsao R, Shahidi F (eds.), Cereals and pulses: Nutraceutical properties and health benefits. Wiley-Blackwell, Inc. Oxford, OX4 2DQ, 2012 pp. 273-308.

35. Saha SK, Lee SB, Won J, Choi HY, Kim K, Yang GM, Dayem AA, Cho SG. Correlation between Oxidative Stress, Nutrition, and Cancer Initiation. Int. J Mol. Sci. 2017; 18: 1544.

36. Osuntoki A, Korie I. Antioxidant activity whey from milk fermented with Lactobacillus species isolated from Nigerian fermented foods. Food Technol. Biotech. 
2010; 48: 505-511.

37. Abubakr MAS, Hassan Z, Eswai GSM. Evaluation of antioxidant activity of skim milk hydrolysate fermented with lactic acid bacteria. Acta Biol. Malays. 2012; 1: 85-93.

38. Xiao Y, Xing G, Rui X, Li W, Chen X, Jiang M, Dong $M$. Enhancement of the antioxidant capacity of chickpeas by solid state fermentation with Cordyceps militaris SN-18 J. Funct. Foods, 2014; 10: 210-222.

39. McCue PP, Shetty K. Phenolic antioxidant mobilization during yogurt production from soymilk using Kefir cultures. Process Biochem. 2005; 40: 1791-1797.

40. Lee YL, Yang JH, Mau JL. Antioxidant properties of water extracts from Monascus fermented soybeans. Food Chem. 2008; 106: 1128-1137.

41. Dueñas M, Fernández D, Hernández T, Estrella I, Muñoz R. Bioactive phenolic compounds of cowpeas (Vigna sinensis $\mathrm{L}$ ). Modifications by fermentation with natural microflora and with Lactobacillus plantarum ATCC 14917. J. Sci. Food Agric. 2005; 85: 297-304.

42. Yust MM, Millan-Linares MD, Alcaide-Hidalgo JM, Millan F, Pedroche J. Hypocholesterolemic and antioxidant activities of chickpea (Cicer arietinum L.) protein hydrolysates. J. Sci. Food Agric. 2012; 92: 1994-2001.

43. Kou XH, Gao J, Xue ZH, Zhang ZJ, Wang H, Wang $X$. Purificationand identification of antioxidant peptides from chickpea (Cicer arietinum L.) albumin hydrolysates. LWT - Food Sci. Technol. 2013; 50: 591-598.

44. Torres-Fuentes C, Alaiz M, Vioque J. Chickpea chelating peptides inhibit copper-mediated lipid peroxidation. J. Sci. Food Agric. 2014; 94: 3181-3188.

45. Torres-Fuentes C, Contreras MDM, Recio I, Alaiz $M$, Vioque J. Identification and characterization of antioxidant peptides from chickpea protein hydrolysates. Food Chem. 2015; 180: 194-202.

46. Li YW, Li B, Characterization of structure-antioxidant activity relationship of peptides in free radical systems using QSAR models: Key sequence positions and their amino acid properties. J. Theor. Biol. 2013; 318: 29-43.
47. Saiga A, Tanabe S, Nishimura T. Antioxidant activity of peptides obtained from porcine myofibrillar proteins by protease treatment. J. Agric. Food Chem. 2003; 51: 3661-3667.

48. Kim J, Choi, JN, Kang D, Son GH, Kim YS, Choi HK, Kwon $\mathrm{DY}$, Lee $\mathrm{CH}$. Correlation between antioxidative activities and metabolite changes during Cheonggukjang fermentation. Biosci. Biotechnol. Biochem. 2011; 75: 32-739.

49. Zhao D, Shah NP. Changes in antioxidant capacity, isoflavone profile, phenolic and vitamin contents in soymilk during extended fermentation. LWT- Food Sci. Technol. 2014; 58: 454-462.

50. Chandra-Hioe MV, Wong $\mathrm{CH}$, Arcot J. The Potential Use of Fermented Chickpea and Faba Bean Flour as Food Ingredients. Plant Foods Hum. Nutr. 2016; 71: 90-95.

51. Lin CH, Wei YT, Chou CC. Enhanced antioxidative activity of soybean koji prepared with various filamentous fungi. Food Microbiol. 2006; 23: 628-633.

52. Abu-Salem FM, Mahmoud MH, El-Kalyoub MH, Gibriel AY, Abou-Arab A. Characterization of Antioxidant Peptides of Soybean Protein Hydrolysate. IJSRIT, 2013; 7: 522-526.

53. Chang YW, Alli I, Molina AT, Konishi Y, Boye JI. Isolation and characterization of chickpea (Cicer arietinum L.) seed protein fractions. Food Bioprocess. Tech. 2012; 5: 618-625.

54. Sánchez-Vioque R, Clemente A, Vioque J, Bautista J, Millán F. Protein isolates from chickpea (Cicer arietinum L.): chemical composition, functional properties and protein characterization. Food Chem. 1999; 64: 237-243.

55. Krishnan HB, Kim WS, Jang S, Kerley MS. All three subunits of soybean beta-conglycinin are potential food allergens. J. Agric. Food Chem. 2009; 57: 938-943.

56. Singh-Ackbarali D, Maharaj R. Sensory Evaluation as a Tool in Determining Acceptability of Innovative Products Developed by Undergraduate Students in Food Science and Technology at The University of Trinidad and Tobago. Journal of Curriculum and Teaching, 2014; 3: 10-27. 